\title{
Analysis of indoor air quality in surgical operating rooms using experimental and numerical investigations
}

\author{
Najla El Gharbi ${ }^{1,2, a}$, Ahmed Benzaoui ${ }^{2}$, Essam Eldin Khalil ${ }^{3}$ and Ramiz Kameel ${ }^{3}$ \\ 1 Center for Renewable Energy Development, PO Box 62 Bouzareah 16340 Algiers, Algeria \\ 2 University of Sciences and Technology Houari Boumediene, Faculty of Physics, Po. Box 32 El Alia Bab Ezzouar, \\ 16111 Algiers, Algeria \\ 3 Cairo University - Faculty of Engineering, Egypt, Gamaet El Qahera St. Giza, Giza, Egypt
}

Received 24 June 2011, Accepted 2 November 2011

\begin{abstract}
The present work fosters experimental measurements and mathematical modelling techniques to primarily determine the thermal and the relative humidity characteristics in the air-conditioned surgical operating room. The present work also demonstrates the effect of the various designs of surgical operating rooms and operational parameters on the flow pattern and temperatures characteristics. This study is a part of a more comprehensive investigation of the more important factors affecting the air environments in surgical operating room. Measured and predicted temperatures and relative humidity profiles are shown to be in good agreement. The present paper introduces several recommendations regarding the optimum design requirements of operating rooms to provide hygiene and comfort environment. Low humidity affects comfort and health. The present work offers examples of measured relative humidity profiles in an operating room in (New Kasr El-Aini Teaching Hospital - 1200 beds - Cairo University - Egypt). These experimental results were carried out to verify the proposed numerical procedure and particularly in the vicinity of the supply outlets and operating table.
\end{abstract}

Key words: Surgical operating rooms / aerodynamics simulation / turbulent model / comfort / airflow / indoor air quality

\section{Introduction}

Hospitals and other health care facilities are complex environments that require ventilation for comfort and to control hazardous emissions. Indoor air quality is more critical in health care facilities due to many dangerous microbial and chemical agents present and the increased susceptibility of the patients. To build ventilation system that is capable of efficiently fulfilling all requirements, often even contradictory, is a great challenge. In addition, the importance of good indoor climate is not yet unanimously recognized. Therefore, nosocomial infections due to contaminated air continue to cause unnecessary costs and sufferings, and health care personnal remain subject to several occupational exposure risks. In addition, indoor climate fails often to be comfortable.

Even though airborne spread infectious agents are relatively few compared to total number of infectious microbes, we must be aware of those. There are several bacteria, viruses, and fungi that can be transmitted through the air. The possibility of airborne infection varies much

${ }^{a}$ Corresponding author: n.elgharbi@cder.dz with the type of the microbe. Medical intervention of certain diseases changes the patient to become exquisitely susceptible to common opportunistic environmental microbes.

There are several factors affecting the hygiene in the surgical operating rooms. The HVAC system plays an important role to maintain the hygiene in the operating rooms.

\section{Experimental simulation}

Experimental facility: The HVAC system that serves the hospital under consideration is all air system (variable air volume VAV). The HVAC system is in operation most of year. In new Kasr El-Aini Teaching Hospital, the air conditioning system of surgical operating rooms was designed as an all air system, which supplies the different operating rooms in the hospital by air. The supplied airflow to the operating rooms was discharged through four square ceiling perforated diffusers each $0.6 \times 0.6 \mathrm{~m}$; the air was supplied through a High-Efficiency. 


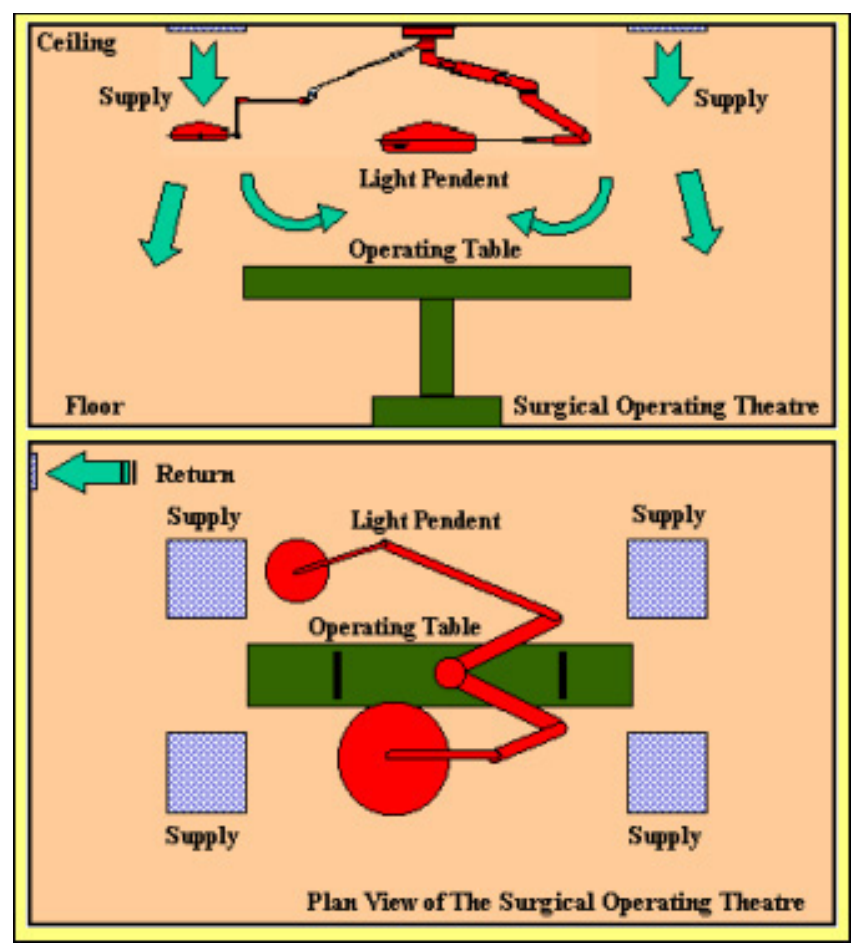

Fig. 1. Schematic layout of the surgical operating room (elevation and plan views).

Particulate Air Filter (HEPA): the four supply diffusers in each surgical operating room had the same relative dimensions in each room. Figure 1 represents a schematic layout of the surgical operating rooms in the New Kasr El-Aini Teaching Hospital. It also indicates the positions of the supply air outlets relative to operating table, which was located in the center of the room. The present experiments were performed with the presence of the room furniture, such as the operating table, operating devices, operating lamp, and all additional accessories. The room dimensions are $6.6 \mathrm{~m}$ in length $(L), 4.0 \mathrm{~m}$ in width $(w)$, and $3.0 \mathrm{~m}$ in height $(H)$. The operating table has a length of $2.0 \mathrm{~m}$ and a width of $0.5 \mathrm{~m}$, and is $1.0 \mathrm{~m}$ high. Four ceiling square perforated supply air diffusers were located at the ceiling of the room with dimensions of $0.6 \mathrm{~m} \times 0.6 \mathrm{~m}$; their centres were located at $X, Z$ equal to $(1.7,1.3),(4.9,1.3),(4.9,2.7)$, and $(1.7,2.7)$ as shown in Figure 1. The extract ports were located on the left wall with dimensions of $0.5 \mathrm{~m} \times 0.3 \mathrm{~m}$ and $0.5 \mathrm{~m} \times 0.2 \mathrm{~m}$; the lower port center point is located at $0.75 \mathrm{~m}$ from the floor. The higher extract port center point is located at $2.25 \mathrm{~m}$ from the floor [1].

Experimental procedure: Measurements were obtained in the vicinity of the supply grills by dividing the measuring locations to $8 \times 8$ points at $Y$ equal to $2.95 \mathrm{~m}, 2.9 \mathrm{~m}, 2.8 \mathrm{~m}$, and $2.7 \mathrm{~m}$ respectively. Measurements were obtained in the vicinity of the operating table between $1.0 \mathrm{~m}$ and $2.0 \mathrm{~m}$ high above room finished floor. Heated thermocouple anemometer was used. Its probe has a semi-sphere shape with a diameter of $1.0 \mathrm{~mm}$, and was supported in separate telescopic support of a cylindrical
Table 1. Proposed airside designs.

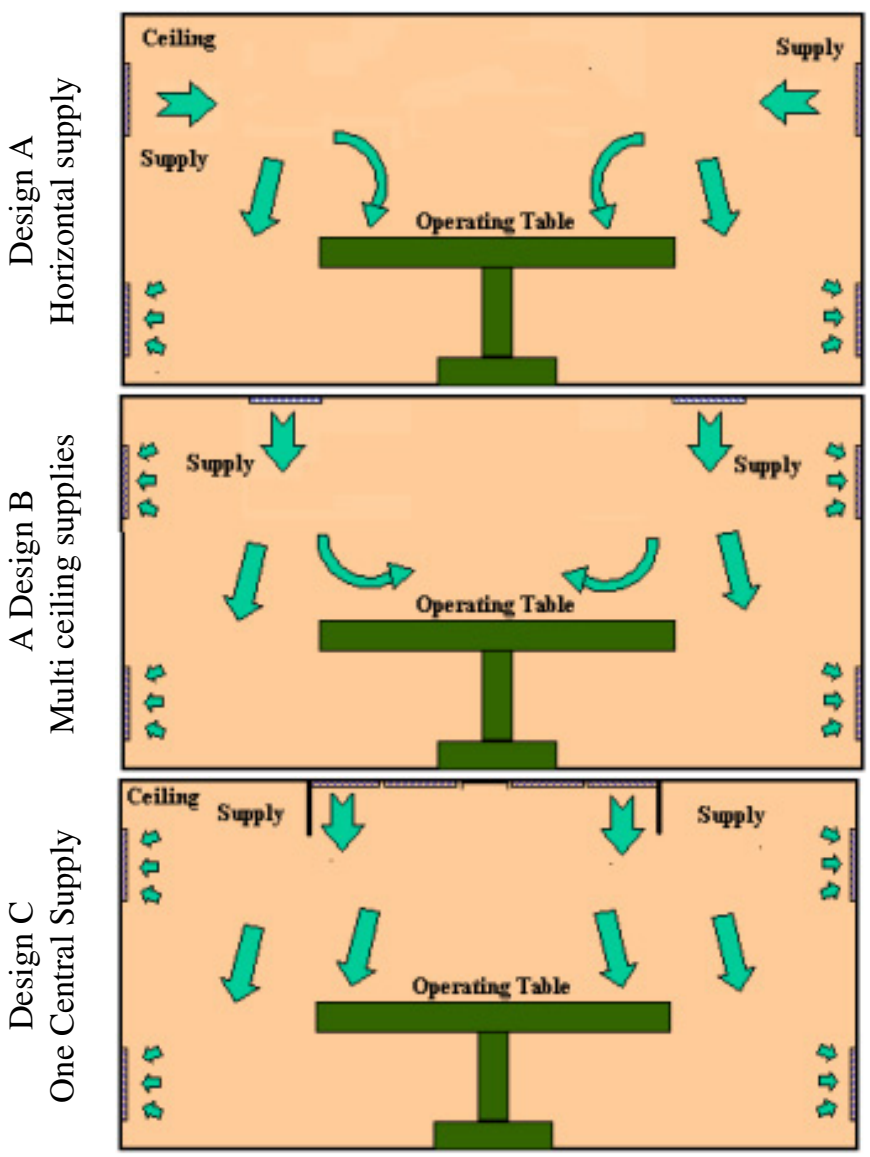

shape with a diameter equals to $12.0 \mathrm{~mm}$ at its base position. That separate telescope has a maximum length of $675 \mathrm{~mm}$, which allowed measurements from remote distances. The heated thermocouple anemometer measures relative humidity with accuracy of $\pm 2.0 \%$, for more details of the experimental procedure, reference should be made to reference [1].

\section{Proposed airside designs}

The present paper introduces three different airside designs that depend mainly on the available architectural design and the flexibility of this design. Indeed, two of those designs are applied on most of the hospitals around the world. The third design is proposed here to overcome the problems associated with the other two designs. The three designs are illustrated as shown in Table 1. For the vertically downward flow the upper level of extraction is proposed.

\section{Mathematical simulation}

Three time averaged velocity components in $X, Y$, and $Z$ coordinate directions were obtained by solving the 
governing equations using a "SIMPLE Numerical Algorithm" [2-4]. The turbulence characteristics were represented by a modified and appropriately extended twoequation $\mathrm{k}-\varepsilon$ model to account for normal and shear stresses and near-wall functions. Fluid properties such as density, viscosity and thermal conductivity were obtained from references. The present work made use of the Computer Program Fluent[5], which was developed by Fluent Inc. as commercial code. The non-commercial 3DHVAC developed by [6] was also utilized.

\section{Numerical procedure and model validation}

The Computer Program, Fluent is used to solve the time-independent (steady state) conservation equations together with the RNG $\mathrm{k}-\varepsilon$ model $[7,8]$ and the corresponding inlet and wall boundary conditions. The numerical grid divided the space of the surgical operating room into discritized computational cells. The discrete finite difference equations were solved with the SIMPLE algorithm [2]. Solution convergence criterion, was applied at each iteration and ensured the summations of normalized residuals were less than $0.1 \%$ for flow, $k$ and $\varepsilon$, and energy. Previous comparisons between measured and predicted flow pattern, turbulence characteristics, and heat transfer were reported earlier in the open literature utilizing the present computational capabilities (Fluent), reference should be made to these for further details and assessments. The predictions of flow and turbulence characteristics were reported to be in general qualitative agreement with the corresponding experiments and numerical simulations published by others $[1,4]$. The obtained trends are in adequate agreement for engineering purposes.

\section{Results}

\subsection{Experimental results}

The results of relative humidity measurements over the operating table will be presented here in graphical three-dimensional plots. Comparisons between measured and predicted profiles are shown here in Figure 2. The experimental results are presented here at three different levels above the operating table shown in Figure 2 for the geometry indicated in Figure 1. Level " $a$ " is at $0.25 \mathrm{~m}$ above the operating table while levels " $b$ " and " $c$ " are at $0.50 \mathrm{~m}$ and $0.70 \mathrm{~m}$ above the operating table respectively. The results are well identified and indicated higher values near the surgeon stand; these values show a minimum in the middle portion of the table. Figure 2 demonstrated good trend wise agreement between measured and predicted relative humidity; some discrepancies were also observed. These comparisons gave a good indication of the present numerical model capability to predict the airflow characteristics in the vicinity of the internal objects.

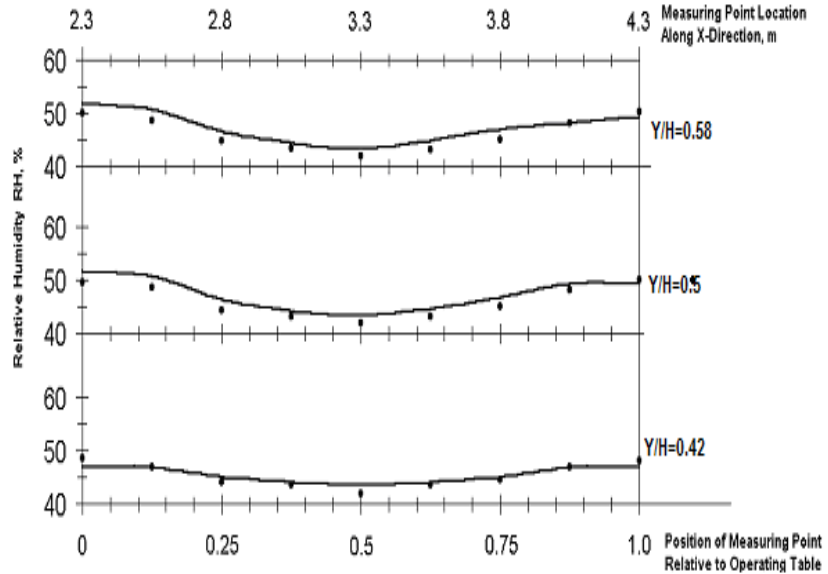

Fig. 2. Comparisons between measured and predicted relative humidity profiles at table.
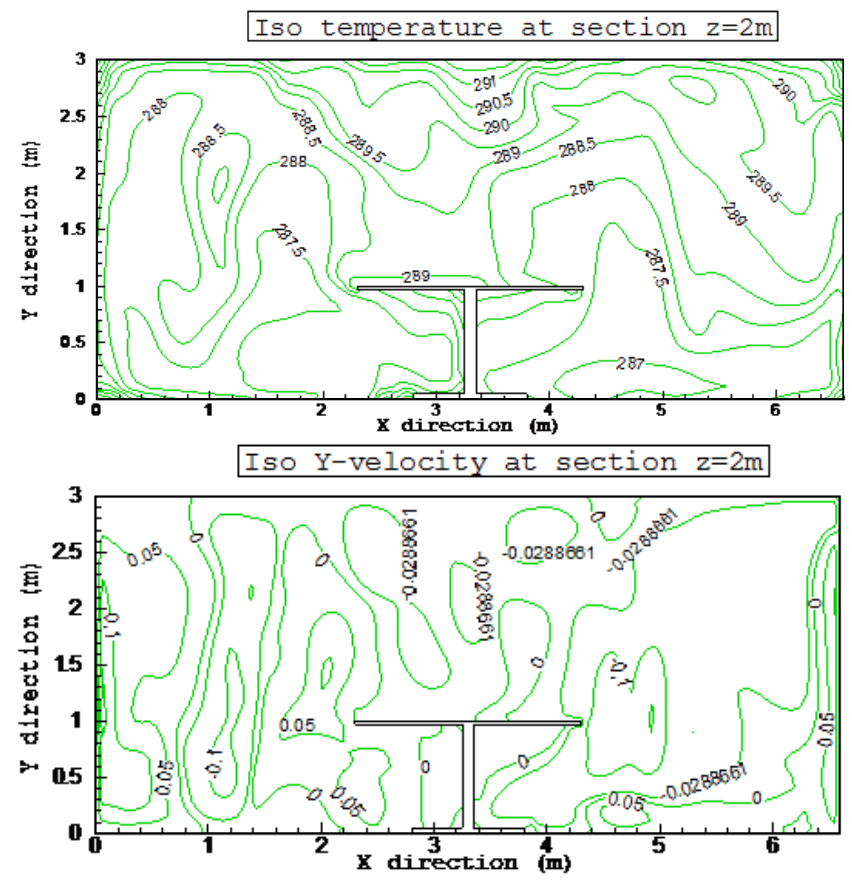

Fig. 3. Predicted temperature and velocity contour maps.

\subsection{Numerical results}

Figure 3 shows the simulation results of the temperature distribution velocity, contours at $Z=2 \mathrm{~m}$, this plane is the orthogonal plane of symmetry cutting across the middle of the operating table, where there is no ceiling supply grill. Figure 4 shows the simulation results of the temperature and velocity contours at $Y=1.25 \mathrm{~m}$, which is the operating plane at the patient's upper surface level. The temperature contours shown in Figures 3 and 4 , are based on an inlet air temperature of $286 \mathrm{~K}$. It can be seen that for both vertical and horizontal planes, the temperature variation at the occupancy zone is not more than $3{ }^{\circ} \mathrm{C}$, which satisfies the prevailing norms. The 

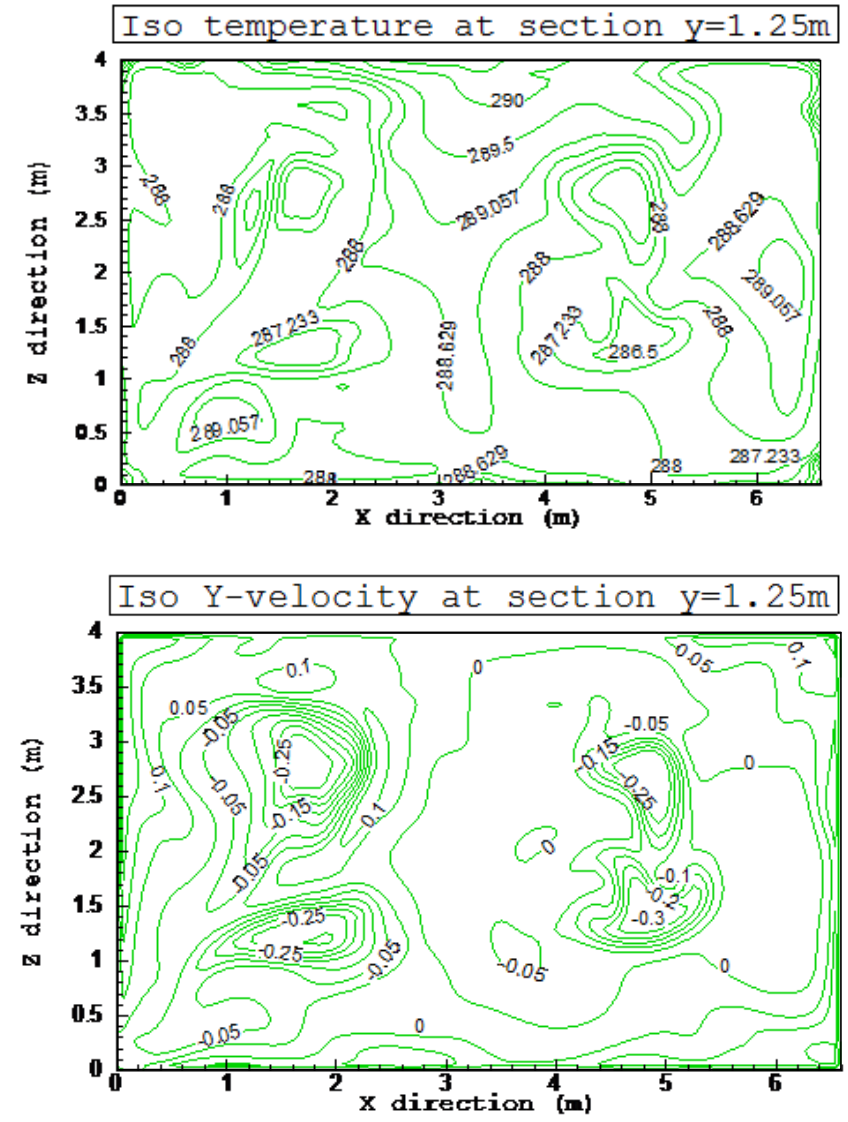

Fig. 4. Predicted temperature and velocity contours.

upper corners of the room are also the worst positions for recirculation zones to exist.

\section{Discussions and conclusion}

From the HVAC design point of view in this surgical operating room, it can be interpreted that the designer focused to sterilize the operating area (over the operating table) by developing an air curtain surrounding the operating table area. The designer established this curtain by injecting the supply air from four individual air supply grills at the corners of the operating area. From figures, one can notice that this design methodology failed and the operating area is not bounded enough to prevent the airflow crossover the boundaries toward the operating area.
The most optimum way to sterilize the operating area is by flooding the operating area by sterilized air to control the airflow in one direction only, which is crossover the boundaries outward the operating area. From the previous results, one can conclude that the airside designs have a strong influence on the relative humidity distribution and consequently on the IAQ (Indoor Air Quality). The location of the supply outlets plays the major role in its distribution. The extraction ports should be located in the right location to correct the errors of the bad selection of the supply outlet positions. The restrictions of the architectural and civil engineering to use a large supply area in the center of the room hinder achievement of good indoor air quality and comfort.

Acknowledgements. The first author express here gratitude towards GTE department (IUT Longwy, Université de Lorraine) for providing necessary facilities, especially for Mr Jean-Louis Dangaville for his advice in the theme of air quality.

\section{References}

[1] R. Kameel, Computer aided design of flow regimes in airconditioned operating theatres, Ph.D. Thesis work, Cairo University, 2002

[2] D.B. Spalding, S.V. Patankar, A calculation procedure for heat, mass and momentum transfer in three dimensional parabolic flows, Int. J. Heat Mass Transf. 15 (1974) 1787

[3] B.E. Launder, D.B. Spalding, The numerical of computation of turbulent flows, Comput. Methods Appl. Mech. Eng. 3 (1974) 269

[4] E.E. Khalil, Indoor Air Quality, Airborne Infection Control and Ventilation Efficiency in Hospital Operating Rooms, Topc-00075-2010, Proceedings ASHRAE_IAQ2010, 2010, Malaysia

[5] Fluent Inc. 2005. Fluent 6.3 user's guide

[6] E.E. Khalil, Flow Regimes Interactions in Air Conditioned Spaces, Proc. 3rd Jordanian Mechanical \& Industrial Engineering Conference, 1999, pp. 79-93

[7] T.T. Chow, S. Ward, J.P. Liu, F.C.K. Chan, Air flow in hospital operating theatre: Hong Kong experience, Proceeding of Healthy Building, Finland 2000, Vol. 2

[8] N. El Gharbi, Modélisation et simulation du transfert de chaleur et de masse dans un espace confiné, Application au conditionnement d'air d'une salle de chirurgie, M.Sc Thesis, Houari Boumediene University, Algeria, 2007 